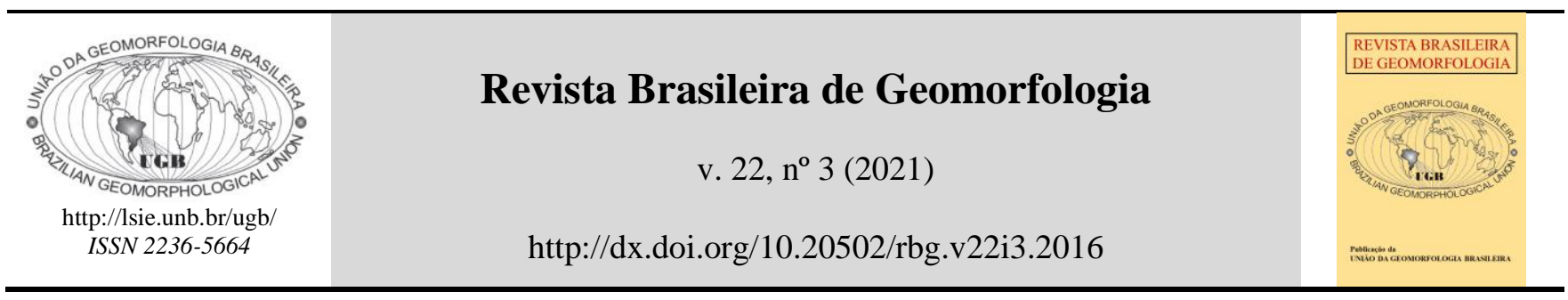

Artigo de Pesquisa

\title{
Rearranjos de drenagem na porção setentrional da Bacia
}

\section{Amazônica}

\section{Drainage rearrangements in the northern portion of the Amazonian Basin}

\author{
André Augusto Rodrigues Salgado', Breno Ribeiro Marent 2, Franzmiller Almeida Nascimento ${ }^{3}$, António \\ Alberto Teixeira Gomes ${ }^{4}$ e Stélio Soares Tavares Júnior ${ }^{5}$
}

\footnotetext{
${ }^{1}$ Professor Associado da Universidade Federal de Minas Gerais - Departamento de Geografia/Instituto de Geociências, Universidade Federal de Minas Gerais (UFMG). Avenida Presidente Antônio Carlos, 6627 - Pampulha, Belo Horizonte/MG, CEP: 31270-901. E-mail: aarsalgadoufmg@gmail.com

ORCID: https://orcid.org/0000-0001-7679-5944

${ }^{2}$ Doutor em Geografia pela Universidade Federal de Minas Gerais (UFMG). E-mail: brenomarent@gmail.com

${ }^{3}$ Professor Adjunto Universidade Federal de Roraima - Educação do Campo. Campus do Paricarana - Universidade Federal de Roraima - Bloco II do CEDUC, Boa Vista/RR, CEP: 69304-000. E-mail: geomiller23@gmail.com

4 Professor Adjunto da Universidade do Porto. Faculdade de Letras da Universidade do Porto. Via Panorâmica, s/n, Porto - Portugal. Código Postal: 4150564. E-mail: albgomes@gmail.com

ORCID: http://orcid.org/0000-0002-1764-0659
}

5 Professor Associado da Universidade Federal de Roraima - Departamento de Geologia/Instituto de Geociências, Universidade Federal de Roraima (UFRR). Avenida Ene Garcez, 2413 - Bairro Aeroporto, Boa Vista/RR, CEP: 69.304-000. Email: stelio.tavares@ufrr.br

ORCID: https://orcid.org/0000-0001-7649-2994

Recebido: 04/09/2020; Aceito: 09/11/2020; Publicado: 01/07/2021

Resumo: A Bacia Hidrográfica do rio Amazonas é a de maior área e volume de água do planeta. Sua elevada dimensão originalmente foi interpretada como resultado do clima e da configuração geológica da América do Sul. Entretanto, nos últimos anos uma série de estudos tem apresentado evidências de que amplos processos de rearranjo de drenagem estariam ocorrendo na região e que estes favoreceram a expansão da Bacia Amazônica. Entre esses amplos processos destacam-se estudos que afirmam que a alta bacia hidrográfica do rio Branco fluía em direção ao rio Essequibo e teria sido capturada pela Bacia Amazônica. Entretanto, os estudos que afirmam isso não apresentam evidências morfológicas para esse rearranjo de drenagem. Neste contexto, através de sensoriamento remoto, geoprocessamento, análises cartográficas e trabalhos de campo, o presente trabalho avaliou as evidências morfológicas que poderiam comprovar processos de rearranjo de drenagem na alta bacia hidrográfica do rio Branco na Amazônia Setentrional. Os resultados permitiram identificar uma série de evidências geomorfológicas integradas entre si e indicativas de processos de pirataria fluvial, com destaque para cotovelos de drenagem, baixos divisores e paleocanais fluviais. Sendo assim, confirmam que no passado os rios Uraricoera e Tacutu - formadores do 
rio Branco - integravam a Bacia Hidrográfica do rio Essequibo que desagua no Caribe. Porém, graças à erosão regressiva das paleo-cabeceiras do rio Branco foram interceptados e integrados à Bacia Amazônica.

Palavras-chave: Palavras-chave: Rio Branco; Captura Fluvial; Rio Essequibo.

Abstract: The Amazonas River Basin is the biggest in area and volume in the planet. Its high dimension was originally interpreted as a result of the climate and geological configuration of South America. However, in recent years, a series of studies has shown evidence that extensive drainage rearrangement processes are taking place in the region and that these favored the expansion of Amazon Basin. Among these broad processes, studies stand out that claim that the upper hydrographic basin of the Branco River flowed towards the Essequibo River and would have been captured by the Amazon Basin. However, the studies that affirm this do not present morphological evidence for this drainage rearrangement. In this context, through remote sensing, geoprocessing, cartographic analysis and fieldwork, the present work evaluated the morphological evidence that could prove drainage rearrangement processes in the upper hydrographic basin of the Branco River in the Northern Amazon. The results allowed to identify a series of geomorphological evidences integrated with each other and indicative of fluvial piracy processes, with emphasis on elbow drainages, low dividers and river paleochannels. Therefore, they confirm that in the past the Uraricoera and Tacutu rivers - which form the Branco River - were part of the Essequibo River Basin, that flows into the Caribbean. However, thanks to the regressive erosion of the paleo-headwaters of the Branco River, they were intercepted and integrated into the Amazon Basin.

Keywords: Branco River; River Capture; Essequibo River.

\section{Introdução}

A Bacia Hidrográfica do rio Amazonas é a de maior área e descarga do mundo e, graças a sua dimensão, biodiversidade e importância climática e ambiental, constitui região prioritária para investigações científicas. Obviamente, entre essas investigações destacam-se aquelas que estudam os processos fluviais, as características e evolução da sua densa rede de drenagem. No entanto, apesar da bacia hidrográfica do rio Amazonas já ter sido objeto de uma ampla gama de pesquisas, inclusive de várias que investigaram a organização e reorganização de sua rede de drenagem (HOORN et al., 1995, 2010; 2017; SACEK, 2014), chama atenção terem sido poucos os estudos que abordaram processos clássicos de captura fluvial.

A pirataria fluvial é um processo importante não só por alterar os fluxos de água e sedimentos, mas também por seus impactos na biodiversidade, pois permite a migração de espécimes entre diferentes bacias hidrográficas. Atualmente sabe-se que o fenômeno de migração de espécimes aquáticas de águas doces foi muito recorrente em toda a América do Sul a leste da Cordilheira dos Andes e envolveu diversos momentos de conexão, desconexão e reconexão entre as diferentes bacias hidrográficas que drenam essa porção do continente (ALBERT; REIS, 2011). No entanto, os processos de pirataria fluvial de maior dimensão, ou seja, aqueles que envolveram a migração entre bacias hidrográficas de grandes canais e extensas áreas, podem ser considerados raros (BISHOP, 1995). Apesar dessa raridade, a pirataria fluvial de elevada magnitude ocorre na Amazônia Setentrional. Stokes, Goldberg e Perron (2018) comprovam que, ao longo dos últimos duzentos anos, cerca de $40.000 \mathrm{~km}^{2}$ da alta bacia hidrográfica do rio Orenoco está pouco a pouco se transferindo para o rio Negro, afluente direto do rio Amazonas.

Aparentemente, essa não foi a única grande pirataria fluvial que ocorreu na Amazônia Setentrional durante o Quaternário. Em área localizada mais a leste da captura relatada por Stokes et al. (2018), Guerra (1957), Cremon et al. (2016) e Nascimento, Salgado e Gomes (2019) apontam para existência de indícios de uma outra grande 
reorganização de drenagem. Esta teria ocorrido na alta bacia hidrográfica do rio Branco, principal afluente do rio Negro (Figura 1). Os indícios indicam que os rios Uraricoera e Tacutu - formadores do rio Branco - no passado fluíam em direção ao rio Essequibo e, consequentemente, para o mar do Caribe. Vale ressaltar que dentre os três trabalhos acima citados, aquele que apresentou evidências mais contundentes dessa pirataria fluvial foi o de Cremon et al. (2016). Os autores, ao estudarem a porção inferior - Sul - da Bacia Hidrográfica do rio Branco e datarem os depósitos sedimentares localizados na região do Pantanal Setentrional (Figura 1), concluíram que houve uma mudança na deposição de sedimentos do rio Branco há 18,7 mil anos. Relacionaram essa alteração à captura do rio Branco para sul, em um processo que teria origem em uma reativação tectônica que promoveu a subsidência da região do Pantanal Setentrional. O input erosivo causado por essa subsidência teria permitido que as paleocabeceiras de um paleo rio Branco regredissem, interceptassem e capturassem toda a rede de drenagem da porção norte da atual bacia hidrográfica (Figura 1).

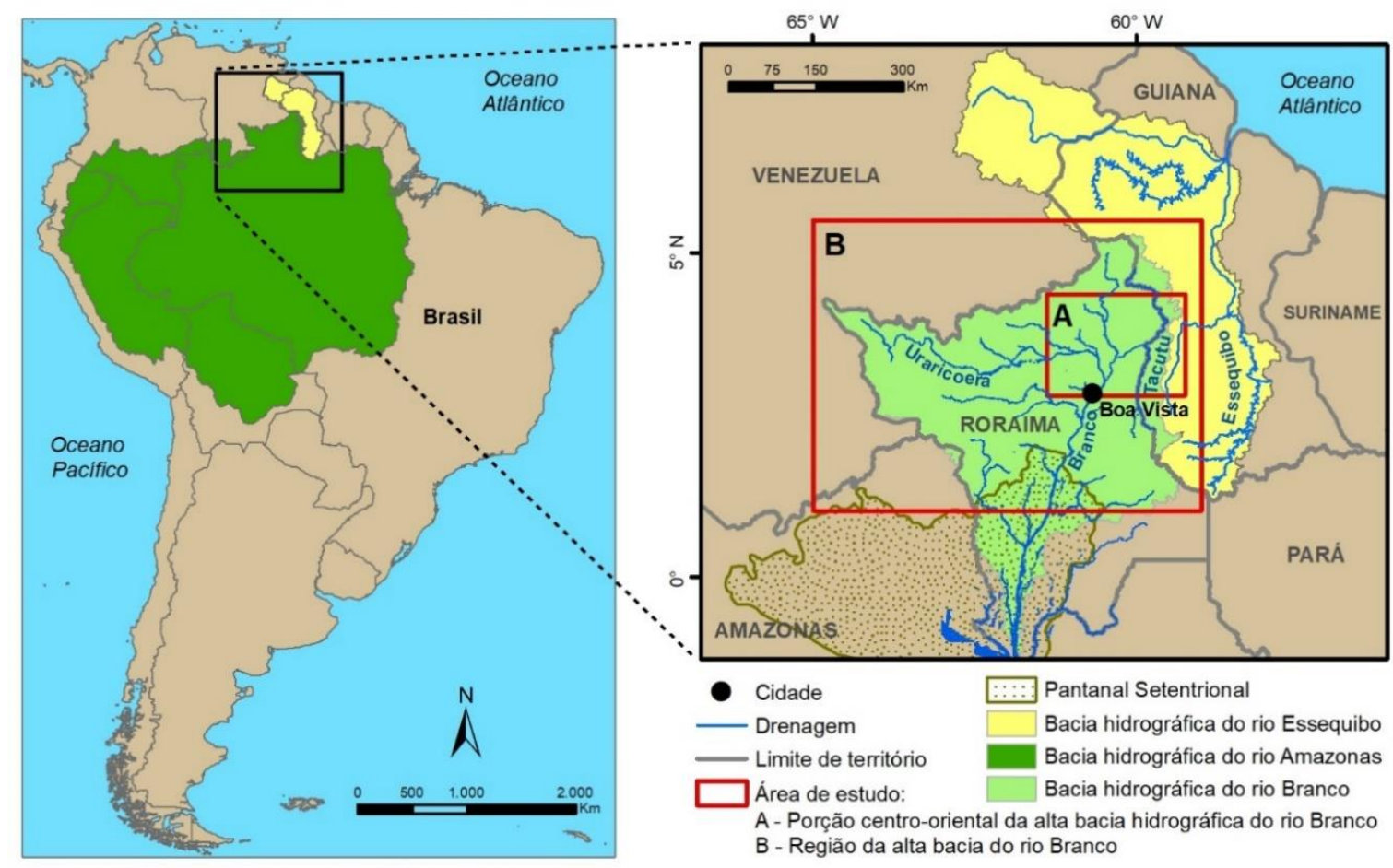

Figura 1: Mapa de localização da área de estudo: (A) Setor centro-oriental da alta bacia hidrográfica do rio Branco; (B) Região da alta bacia hidrográfica do rio Branco.

Embora o trabalho de Cremon et al. (2016) seja bem embasado e conte com geocronologia precisa, ele nunca investigou a alta bacia hidrográfica do rio Branco e nem apresentou evidências morfológicas do processo de pirataria fluvial. Diante dessa lacuna, o presente trabalho investiga a evolução da rede de drenagem da alta bacia hidrográfica do rio Branco no extremo norte do Brasil, em área limítrofe entre o estado brasileiro de Roraima e a República da Guiana (Figura 1). A pesquisa baseou-se em sensoriamento remoto, geoprocessamento e trabalhos de campo, com apresentação de evidências morfológicas que comprovam a pirataria fluvial da alta bacia hidrográfica do rio Branco, bem como explicam seu processo evolutivo. 


\section{2. Área de Estudo}

A alta bacia hidrográfica do rio Branco possui um pouco mais de $130.000 \mathrm{~km}^{2}$ e se localiza quase totalmente em território brasileiro. Situa-se entre as coordenadas geográficas $59^{\circ} 15^{\prime}$ e $61^{\circ} 40^{\prime}$ de longitude oeste e $02^{\circ} 47^{\prime}$ e $04^{\circ} 10^{\prime}$ de latitude norte (Figura 1). Drena litologias aflorantes no setor norte do Cráton Amazônico de idade paleo a mesoproterozoicas (WYNN et al., 1993). Esta região de Roraima, se caracteriza pelos limites entre os domínios litoestruturais Parima de trend estrutural predominante NW-SE, Surumu com trend preferencial ENE-WSW e Guiana Central com domínio de estruturas NE-SW, de acordo com o modelo proposto para o estado por Reis e Fraga (1998) e Reis et al. (2003). Esses domínios englobam rochas gnáissicas diversas orto e paraderivadas, granitódes, corpos vulcânicos e intrusivos de composição granítica e máfica (Figura 2). Eventos tectônicos de caráter extensional condicionados à reativação de estruturas ao longo de linhas de fraqueza crustal, presentes no domínio Guiana Central (REIS et al., 1991), culminaram com a instalação da bacia rift do Tacutu. Os litotipos mesozoicos aflorantes ao longo dessa bacia rift, consistem nos derrames basálticos relacionados à fase pré-rift, sequências siltícas a pelíticas e areníticas da fase rift-ativo (Figura 2). Além dessas sequências, ocorrem com grande expressão regional sedimentos argilo-arenosos e areias eólicas inconsolidadas, representando a fase rift-passivo em idade cenozoica.

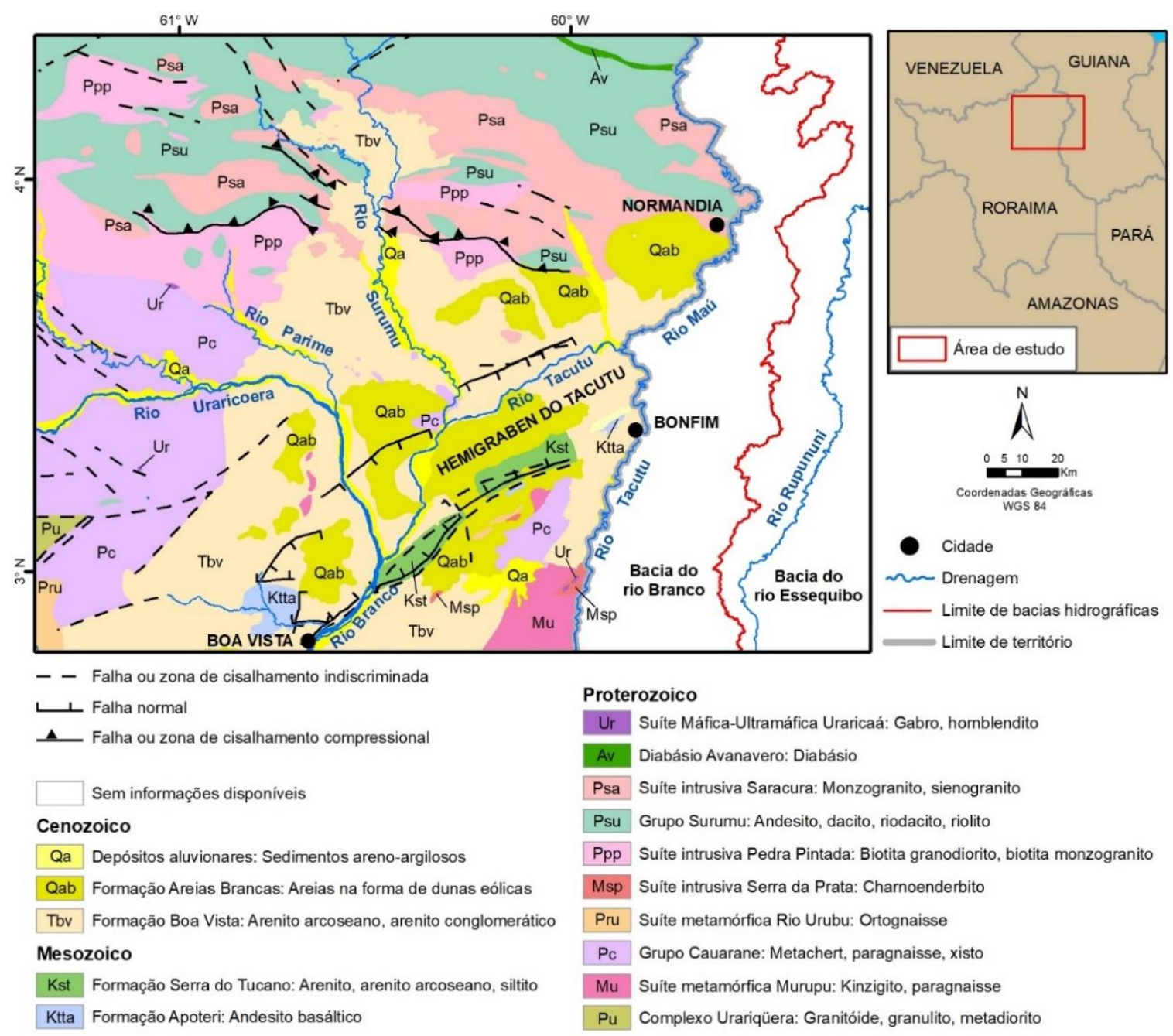

Figura 2: Mapa geológico simplificado da área de estudo. Fonte: CPRM (2004).

Sobre este quadro litoestrutural se desenvolvem formas de relevo de dissecação e agradação com denominações propostas por Beserra Neta e Tavares Júnior (2008). No norte, leste e, isoladamente, a oeste, nos 
limites da bacia hidrográfica, ocorrem planaltos de interflúvio e serranias. Estes compõem patamares mais dissecados, em contato mais a norte e noroeste com planaltos tabulares, com algumas formas conhecidas regionalmente por tepuis, que por vezes superam os dois mil metros de altitude, caso do Monte Roraima. No setor mais central e sul da área predomina uma superfície de pediplano, levemente ondulada, cuja monotonia é interrompida por relevos residuais estruturados em rochas magmáticas e supracrustais paleoproterozoicas e nos derrames basálticos mesozoicos. No interior da bacia rift do Tacutu ressalta-se um modelado de dissecação caracterizado por feições de morros e serras correspondentes a região conhecida como serra do Tucano. Por fim, destacam-se os modelados de agradação constituídos por depósitos arenosos inconsolidados, que formam planícies de inundação conectadas com terraços fluviais que seguem os padrões semi - meandrantes, por vezes meandrantes dos rios Uraricoera, Surumu, Tacutu e Branco.

O clima regional é tropical sub-úmido com temperatura média anual circulando em torno dos $28^{\circ}$ (BARBOSA, 1997). O período seco se estende de setembro até março e as precipitações médias anuais variam entre $1.600 \mathrm{~mm}$ a $1.800 \mathrm{~mm}$. A vegetação natural é a savana que se distribui sobre os relevos aplainados e suavemente ondulados. Ao longo de toda a área ocorre a formação de enclaves de florestas em meio à savana. Estes enclaves constituem a floresta de transição entre o domínio das savanas e da floresta ombrófila amazônica típica. São comuns também as florestas nas margens dos cursos d'água e, em meio a savana, as veredas de palmeiras (Buriti - Mauritia Flexuosa) (SILVA, 1997).

\section{Procedimentos Metodológicos}

A pesquisa se baseou na confecção de mapas temáticos, na análise de dados obtidos por sensoriamento remoto e oriundos de trabalhos de campo, sendo avaliadas em dois conjuntos espaciais distintos: (1) porção centro-oriental da alta bacia hidrográfica do rio Branco e (2) região da alta Bacia hidrográfica do rio Branco.

Na região centro-oriental da alta Bacia hidrográfica do rio Branco (Figura 1A) foram analisados elementos litoestruturais, topográficos e evidências de depósitos sedimentares. Para compilação e análise do mapa geológico utilizou-se de dados da Companhia de Pesquisa e Recursos Minerais (CPRM, 2004). O Modelo de Elevação Digital - MDE e o mapa de declividade foram confeccionados a partir de dados altimétricos da Shuttler Radar Topography Mission (SRTM), resolução de 30 metros e reprocessamento NASADEM, que incluem melhoramentos de dados de elevação. Tais dados permitiram, ainda, a elaboração de perfis topográficos que evidenciam o modelado da área de estudo e foram compilados em associação ao MDE. Os dados de bacias hidrográficas e da rede de drenagem, utilizados sobre a cartografia geológica e produtos derivados do SRTM, foram obtidas no banco de dados da Agência Nacional de Águas (ANA). As imagens orbitais utilizadas são provenientes do sensor OLI do Landsat 8. Nelas foram aplicados processamentos de correção das interferências dos constituintes atmosféricos e de radiometria para geração da imagem de reflectância. Este procedimento foi adotado, pois a proposta de trabalho visou evidenciar em maior escala de detalhe alvos na superfície, como elementos hidrográficos, morfológicos e deposicionais, tais como: canais fluviais, limites de paleodrenagens, divisores hidrográficos, baixos divisores hidrográficos, cotovelos de drenagem e lobos deposicionais em leque aluvial. Esse conjunto de elementos foi associado ao MDE e mapa de declividade, nos quais procurou-se demonstrar paleoeventos ocorridos na área responsáveis pela reorganização da drenagem. Trabalhos de campo foram efetuados na área de estudo procurando identificar as paleodrenagens evidenciadas nas imagens orbitais.

Na região da alta bacia hidrográfica do rio Branco (Figura 1B), que compreende área de maior extensão regional, foi realizada análise espacial de orientação das drenagens associada aos elementos evidenciados na região 
centro-oriental da alta bacia hidrográfica do rio Branco, procurando fazer a reconstituição paleohidrográfica e de reorganização da rede de drenagem. Como base utilizou-se de dados do MDE com reprocessamento NASADEM, seleção de drenagens compiladas a partir de dados da ANA e de interpretações realizadas a partir dos produtos derivados descritos anteriormente. Tais dados permitiram demonstrar o complexo sistema de reorganização da rede de drenagem que ocorreu na alta bacia hidrográfica do rio Branco.

\section{Resultados e Discussões}

Os resultados obtidos através das análises cartográficas, por sensoriamento remoto e geoprocessamento permitiram verificar na área de estudo uma série de geoformas típicas de rearranjo fluvial, destacando-se entre elas os cotovelos de drenagem e os baixos divisores (Figura 3). De fato, o rio Uraricoera em seu alto e médio curso possui direção geral de oeste para leste, se dirigindo para o rio Essequibo (Figura 1). Entretanto, ao longo da superfície aplainada que domina o centro da área de estudo, em seu baixo curso, graças a dois cotovelos, se redireciona para sul em direção a Bacia Amazônica (figuras 1 e 3). Tais cotovelos situam-se respectivamente, de montante para jusante, a 65 e $63 \mathrm{~m}$ de altitude, enquanto o baixo divisor a $85 \mathrm{~m}$. Na superfície aplainada que separa a Bacia Hidrográfica do rio Uraricoera da Bacia Hidrográfica do rio Tacutu, adjacente ao baixo divisor, dominam as altitudes entre os 80 e $89 \mathrm{~m}$ demonstrando a baixa amplitude da área, sendo as menores cotas altimétricas situadas no interior de lagos sazonais (Figura 3 - perfil A-B e D-D'). 


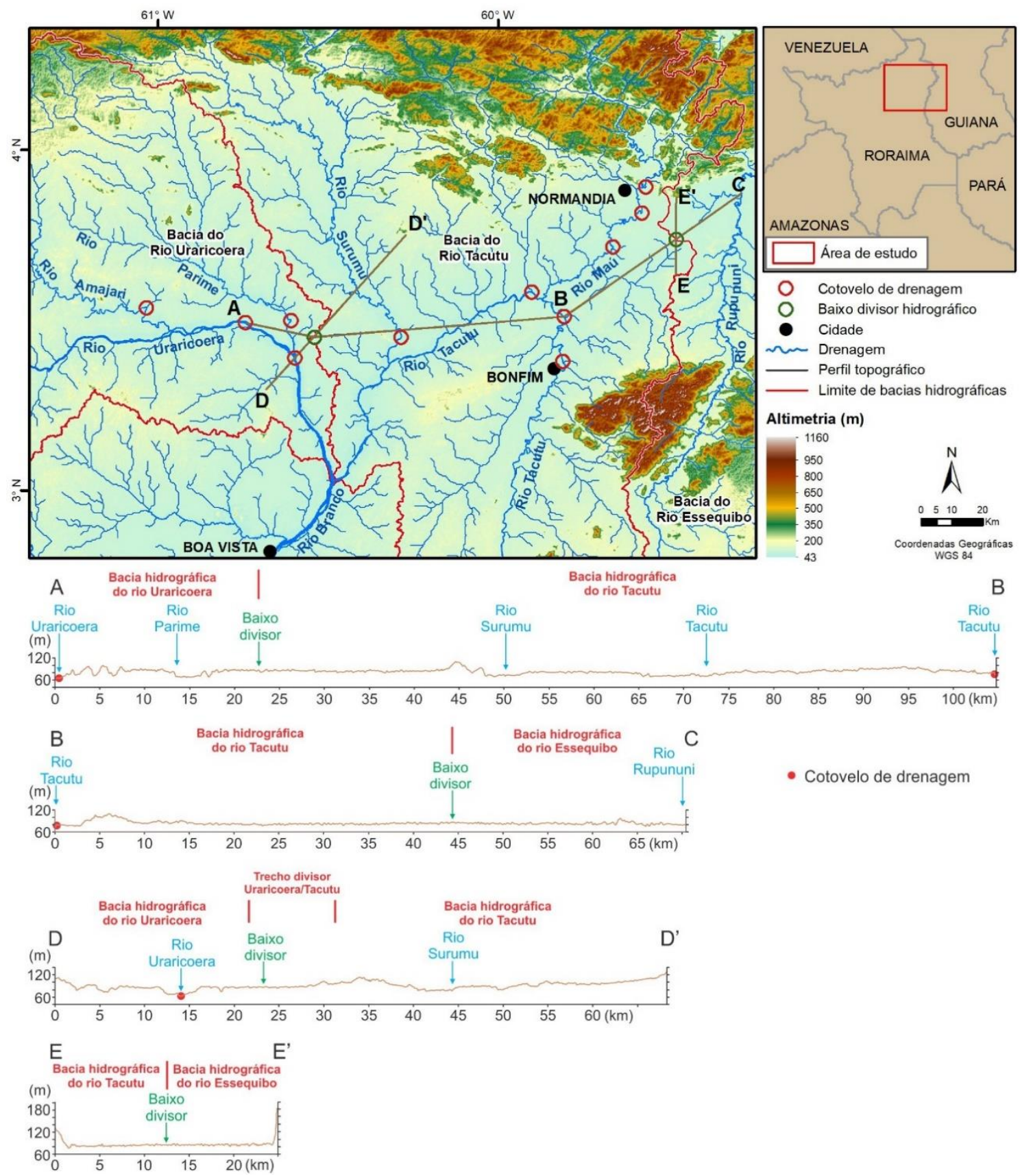

Figura 3: Modelo Digital de Elevação e perfis topográficos da porção centro-oriental da alta bacia hidrográfica do rio Branco.

Por sua vez, o rio Tacutu exibe cotovelos ainda mais pronunciados. Inicialmente segue de sul para norte, mas se redireciona para sudoeste graças a uma série de cotovelos nas proximidades de sua confluência com o rio Maú (figuras 1 e 3). No rio Tacutu os cotovelos situam-se respectivamente a 78, 73, $71 \mathrm{~m}$ de altitude, enquanto o baixo divisor entre as bacias hidrográficas do rio Tacutu/Branco e Rupununi/Essequibo está a $85 \mathrm{~m}$. Na superfície aplainada que separa essas duas bacias hidrográficas dominam as altitudes entre os 79 e $90 \mathrm{~m}$, demonstrando também a baixa amplitude da área (Figura 3 - perfil B-C e E-E'). Não há praticamente nenhum relevo que se destaque entre as bacias hidrográficas dos rios Uraricoera e Tacutu (Figura 3 - perfis A-B' e B-C') e chama a atenção 
que se trata do interflúvio entre duas grandes bacias hidrográficas (Branco e Essequibo) e, estas, mesmo na margem passiva da América do Sul, tendem a ser limitadas por serrarias e montanhas. Ademais, a Bacia Hidrográfica do rio Branco é circundada pelos tepuis, relevos na forma de mesas quartzíticas que tendem a ultrapassar os dois mil metros de altitude em relação ao nível do mar. Nesse sentido, a existência de um baixo divisor com altitude em relação ao nível do mar inferior aos $100 \mathrm{~m}$ é fato marcadamente anômalo e difícil de justificar por um processo que não seja relacionado aos rearranjos de drenagem. A existência desse baixo divisor pode estar relacionada ao graben do Tacutu (Figura 2) que estruturalmente direciona a rede de drenagem regional para o rio Essequibo. Na área de estudo, destacam-se, ainda, outros cotovelos de drenagem em tributários dos rios Uraricoera e Tacutu (Figura 3). Tais anomalias de drenagem encontram-se nos rios Amajari e Parime na Bacia Hidrográfica do rio Uraricoera, e nos rios Surumu e Maú, na do rio Tacutu.

Chama a atenção o fato de os cotovelos de drenagem estarem situados em área extremamente plana, evidenciados nos perfis topográficos. De fato, a amplitude das altitudes do terreno geralmente não alcança os dez metros (perfis topográficos da Figura 3) e a declividade do terreno é, predominantemente, inferior aos $3^{\circ}$ (Figura 4). Imagens orbitais demonstram nessas áreas de baixa declividade paleodrenagens que podem ser reconhecidas por trechos lineares, sinuosos, de tonalidade diferenciada e com presença de lagos intercomunicantes sazonais, além de lobos deposicionais no interior de leque aluvial (Figura 4 - imagens orbitais A1, A2 e A3). Ao que tudo indica tais trechos constituíam a ligação entre os canais fluviais em paleodireção à Bacia Hidrográfica do rio Essequibo, bem como, área de migração lateral dos canais fluviais principais.

Do divisor que separa as bacias hidrográficas dos rios Uraricoera e Tacutu (Figura 4 - imagem orbital A1) existe uma sucessão de paleodrenagens do principal cotovelo até a confluência atual do rio Uraricoera com o rio Tacutu, evidenciando que o rio Uraricoera foi desviado gradativamente de norte para sul. Nesse caso não existiria um único baixo divisor, mas vários, sendo destacado aqui apenas o principal divisor. Chama a atenção nesse caso o controle estrutural exercido pelo Graben do Tacutu e ressalta-se a existência de pronunciado cotovelo no rio Tacutu, antes de sua confluência com o rio Uraricoera, e de cotovelo no rio Surumu condizente com tais elementos estruturais (figuras 2, 3 e 4). Uma outra paleodrenagem também conecta o rio Amajari ao rio Parime e esse aos rios Surumu e Tacutu (Figura 4). Tais evidências morfológicas demonstram uma complexa rede de paleocanais que existiu na região.

O rio Tacutu, entre sua confluência com o rio Surumu e o rio Maú, exibe duas paleodrenagens, uma ao norte e outra a sul em relação ao canal atual, enquanto a montante de sua confluência com o rio Maú exibe um paleocanal a leste (Figura 4 - imagens orbitais A1 e A2). Entre o cotovelo de drenagem mais pronunciado do rio Tacutu e o baixo divisor que separa as bacias hidrográficas dos rios Tacutu/Branco e Rupununi/Essequibo ocorre paleodrenagem que se conecta a paleocanais de leque aluvial (Figura 4 -imagens orbitais A2 e A3). Nascimento, Salgado e Gomes (2019) identificaram na área dois leques aluviais conectando no passado a drenagem do rio Maú ao rio Rupununi/Essequibo, sendo as deposições mais elevadas e antigas ocorrendo de leste para oeste. Contudo, neste trabalhou identificou-se que se trata de um leque aluvial, de aproximadamente $460 \mathrm{~km}^{2}$, com três principais lobos deposicionais, no qual cada um se conecta ao rio Maú em cotovelos de drenagem. Nesse caso, o lobo deposicional 01 apresenta padrão distributário com espraiamento a sudeste, com altitudes que decaem de 98 a 75 $\mathrm{m}$. O lobo deposicional 02 exibe padrão distributário com espraiamento também a sudeste, com elevações que diminuem de 90 a $78 \mathrm{~m}$. O lobo deposicional 03 apresenta padrão distributário com espraiamento a leste, com altitudes que decaem de 84 a $78 \mathrm{~m}$. Tais lobos deposicionais conectam-se em suas extremidades a sudeste formando paleocanais em direção ao rio Rupununi/Essequibo. 

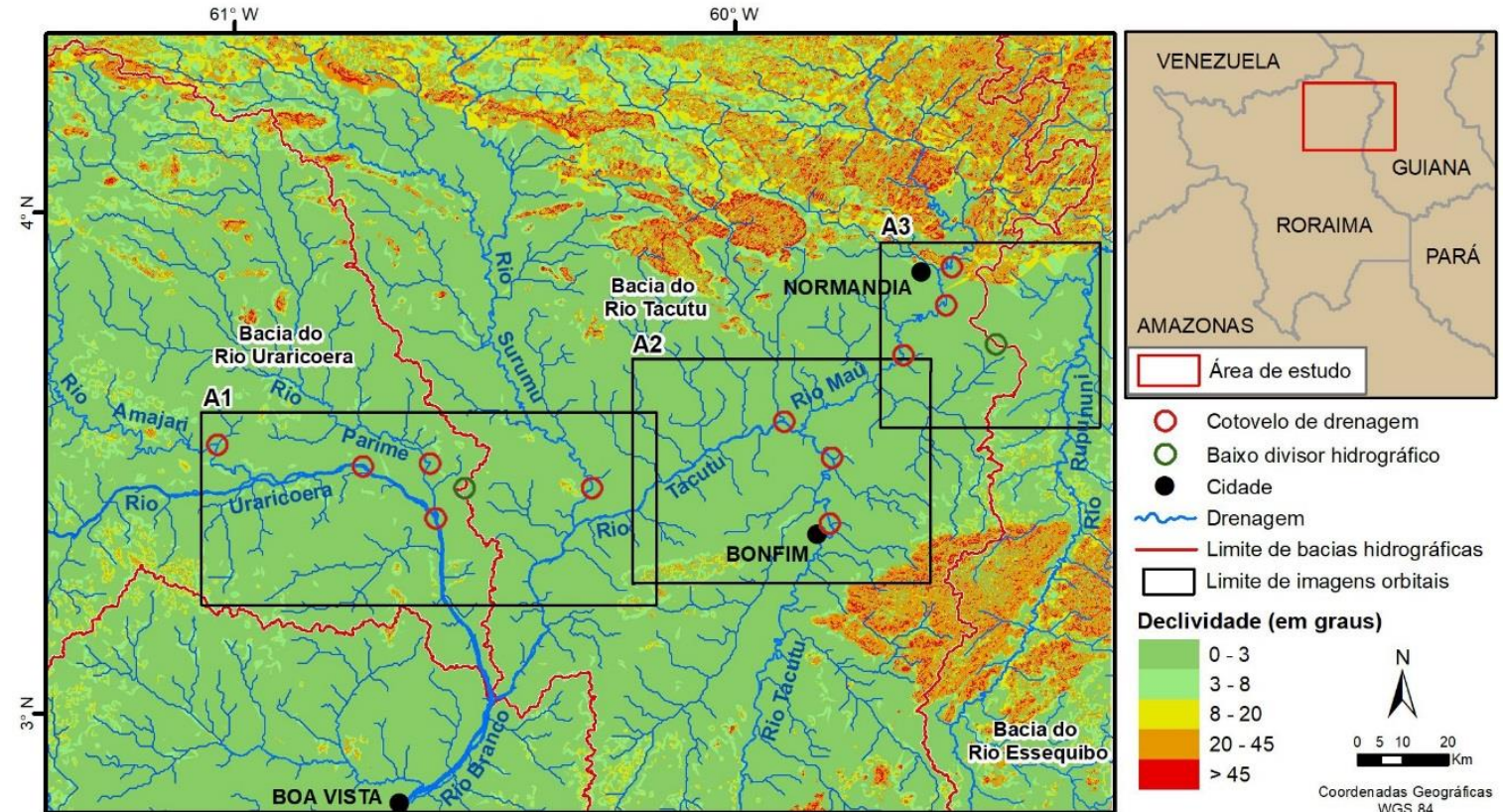

Cotovelo de drenagem

O Baixo divisor hidrográfico

- Cidade

늘 Drenagem

Limite de bacias hidrográficas

Limite de imagens orbitais

Declividade (em graus)
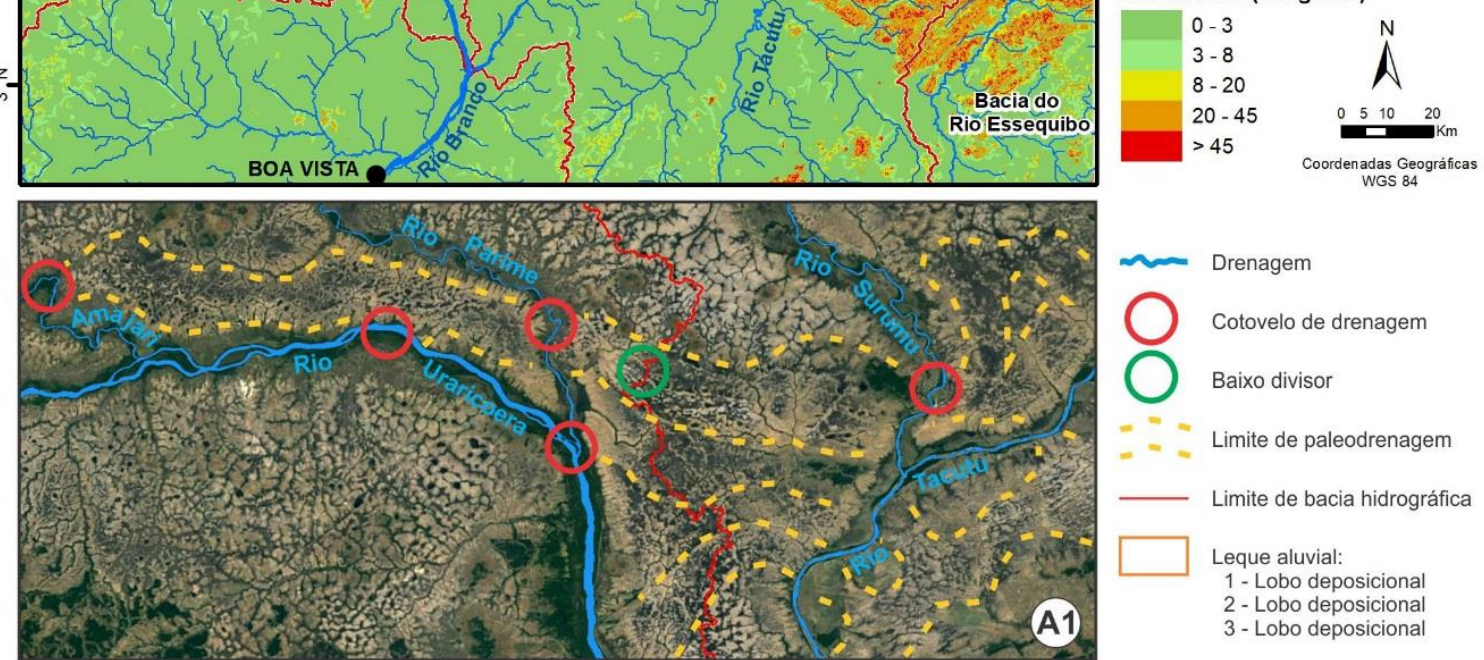

$\sim$ Drenagem

Cotovelo de drenagem

$\bigcirc$ Baixo divisor

- Limite de paleodrenagem

Limite de bacia hidrográfica

Leque aluvial:

1 - Lobo deposiciona

2 - Lobo deposicional

3 - Lobo deposicional
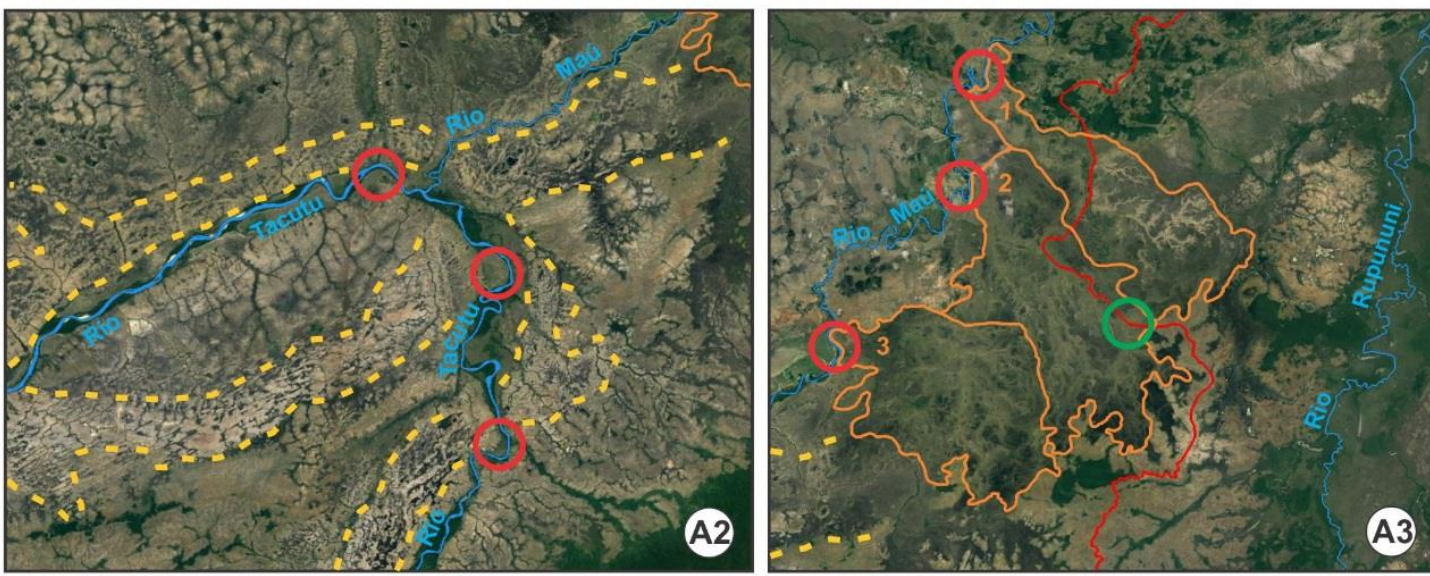

Figura 4: Mapa de declividades com imagem orbital que destaca paleodrenagens que marcam a ligação entre os rios Uraricoera e Tacutu com a Bacia Hidrográfica do rio Essequibo. No interior das paleodrenagens, as manchas escuras constituem lagos sazonais.

Diante do conjunto de observações acima apresentadas, deve-se considerar que os canais dos dois principais formadores do rio Branco - rios Uraricoera e Tacutu - apresentam pronunciados cotovelos que não podem ser 
explicados unicamente pela estruturação geológica do hemigraben do Tacutu ou pelos lineamentos NW da região. Os cotovelos identificados, muitas vezes, possuem ângulos superiores aos que poderiam ser condicionados por essas estruturas e/ou nem sempre estão relacionados a elas (figuras 2 e 3). Paralelamente, as estruturas regionais nem sempre permitem compreender a gênese dos extensos baixos divisores, bem como, tampouco explicam a existência da elevada quantidade de paleocanais que cruzam esses paleodivisores e ligam as diferentes bacias hidrográficas (Figura 4). Sendo assim, fica difícil contestar que a região sofreu processos de rearranjo de drenagens, mesmo que, durante esses processos, alguns canais fluviais tenham se aproveitado das estruturas geológicas para realizar as capturas.

Em paralelo, a extrema planura da região é visualmente percebida na própria paisagem, inclusive no baixo divisor anômalo entre as bacias hidrográficas dos rios Branco (Bacia Amazônica) e Essequibo (Figura 5A e 5B). Merece destaque, além da planura, a existência de depressões no terreno (Figura 5C) que abrigam lagos sazonais (Figura 5D). Tais lagos localizam-se no que seria a continuação da direção original dos rios Uraricoera e Tacutu para o rio Essequibo. Ou seja, em campo é possível perceber uma extensa série de depressões na superfície aplainada por onde escoaram as drenagens e se localizam os baixos divisores. E estas parecem marcar paleotrechos de paleocanais que ligariam as bacias hidrográficas dos rios Uraricoera e Tacutu ao rio Essequibo (Figura 4). Além disso, o entorno dessas depressões é recoberto pelos mesmos depósitos arenosos (Figura 5C) que recobrem o seu fundo (Figura 5D). Isto evidência um processo típico de paleo-deposição fluvial no qual os paleocanais foram migrando gradativamente e depositariam muita areia ao longo dos seus talvegues e margens.
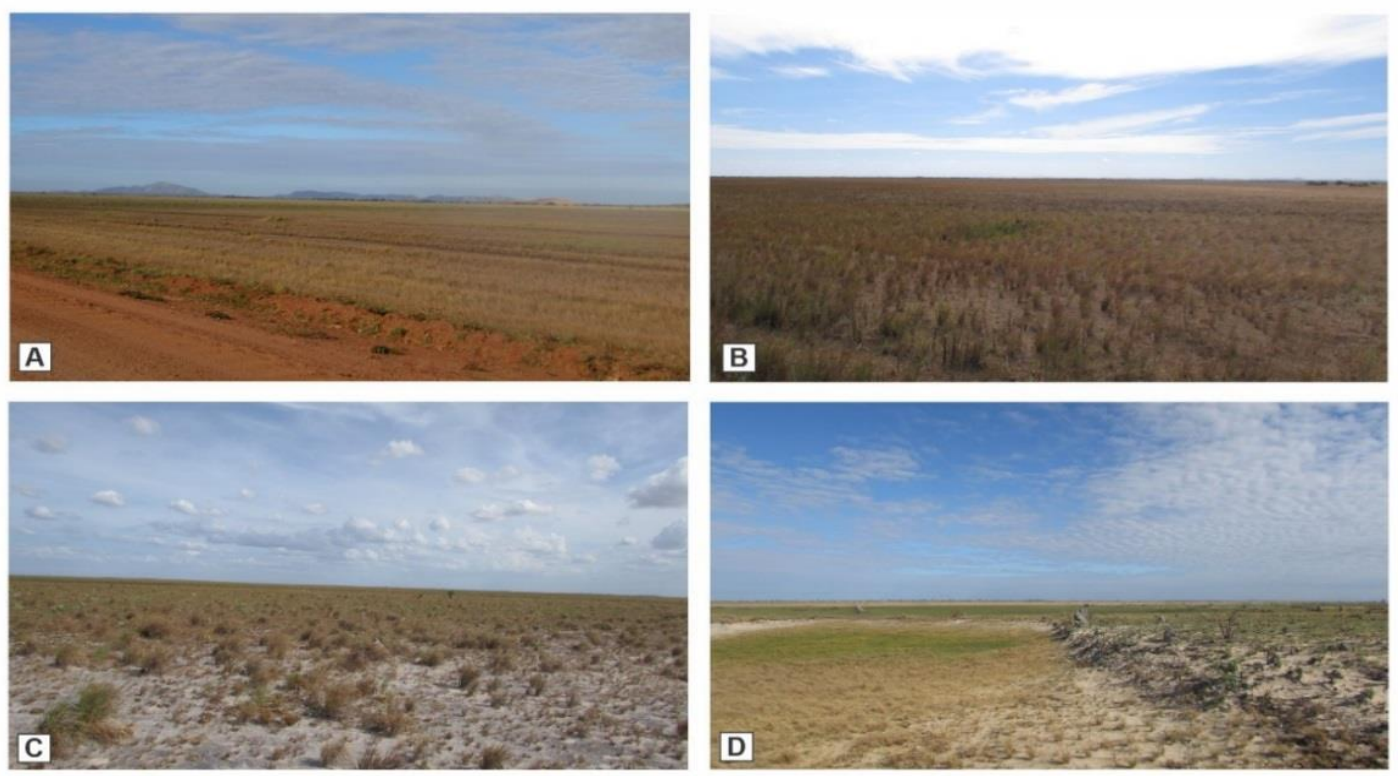

Figura 5: Paisagens típicas da área de estudo no baixo divisor entre as bacias hidrográficas dos rios Branco (Amazonas) e Essequibo. A) No primeiro plano destaca-se a paisagem plana típica do baixo divisor Branco (Amazonas)/Essequibo. No segundo plano estão os morros e serrarias que marcam o limite do baixo divisor; B) Ampla superfície plana localizada ao longo do divisor hidrográfico entre as bacias hidrográficas Branco (Amazonas)/Essequibo; C) Extensa superfície plana rica em lagos sazonais, preenchida por depósitos arenosos (em cor mais clara), na área por onde correria o paleocanal que ligaria o rio Uraricoera com a Bacia Hidrográfica do rio Essequibo; D) Lago sazonal na área por onde correria o paleocanal que ligava o rio Tacutu à bacia hidrográfica do rio Essequibo, preenchida, também, por depósitos arenosos (em cor mais clara). 
De fato, a análise da Figura 4 deixa poucas dúvidas quanto a paleo-ligação entre os rios Uraricoera e Tacutu (Bacia Hidrográfica do rio Branco) com o rio Essequibo. Ainda é possível identificar, de forma praticamente contínua, os paleocanais que drenavam a alta Bacia Hidrográfica do rio Branco para o mar do Caribe. Tanto o rio Uraricoera, quanto o Tacutu, prosseguiam para nordeste e atravessavam o baixo divisor em direção ao rio Essequibo. Esta constatação embasada em quatro fortes evidências - cotovelos de drenagem, baixos divisores, paleocanais preservados e depósitos arenosos - confirmam as conclusões de Cremon et al. (2016) que indicam que toda a alta Bacia Hidrográfica do rio Branco vertia para o mar do Caribe até pelo menos 18,7 mil anos. Considerando o input erosivo causado pela subsidência do Pantanal Setentrional como o mecanismo responsável pelo rearranjo de drenagem (CREMON et al., 2016) e o deslocamento do Gráben do Tacutu, foi proposto o modelo onde, através de uma série de desvios e capturas fluviais, o rio Branco foi reorganizando suas cabeceiras e incorporando à Bacia Amazônica um a um os principais cursos fluviais da região (Figura 6).

Neste modelo, em um primeiro momento a Bacia Hidrográfica do rio Branco se restringia mais ao sul e drenava o baixo e médio curso de seu atual canal principal e dos rios Catrimani e Itã (Figuras 1 e 6 - A). A Bacia Hidrográfica do rio Essequibo abarcava toda a porção do que hoje compreende a alta bacia do rio Branco, compreendendo os rios Apiaú, Mucajaí, Uraricoera, Amaraji, Parime, Surumu, Tacutu e Maú. Neste momento as principais drenagens se orientam para norte ou nordeste direcionando-se para o mar do Caribe. Com a reorganização do rio Uraricoera, seus afluentes e toda a drenagem a jusante desse canal direcionaram-se para a bacia Amazônica, compondo a bacia do rio Branco (Figura 6 - B), redirecionando uma área de drenagem de cerca $85.100 \mathrm{~km}^{2}$. Rios que antes fluíam para norte e nordeste passaram a desaguar a sul deixando inúmeros cotovelos de drenagem e paleocanais na paisagem (Figura 4 - imagens orbitais). Posteriormente, os rios Tacutu e Surumu que se direcionavam para a bacia do rio Essequibo foram capturados incorporando uma área de aproximadamente $32.000 \mathrm{~km}^{2}$, passando a drenar para bacia do rio Branco (Figura $6-\mathrm{C}$ ). Tais cursos d'água também deixaram morfologias de cotovelos de drenagem e paleocanais na paisagem (Figura 4 - imagens orbitais). Nesse caso, o rio Tacutu exibia direção norte e com a captura fluvial passou a apresentar proeminentes cotovelos de drenagem (Figura 3). A última reorganização compreendeu o rio Maú que drenava para a bacia do rio Essequibo e passou fluir para a bacia do rio Branco (Figura 6 - D). Acredita-se que essa captura ocorreu através de vários estágios e estes foram responsáveis pela geração gradativa dos lobos deposicionais no leque do rio Maú que o desviaram progressivamente para Oeste até confluir com o Tacutu, culminando na captura de uma área de aproximadamente $11.625 \mathrm{~km}^{2}$. Dessa forma, no total, uma área de $128.725 \mathrm{~km}^{2}$ foi reorganizada e redirecionada da bacia do rio Essequibo para a bacia do rio Branco.

As evidências morfológicas mostram uma grande quantidade de cotovelos de drenagem e uma complexa rede de paleocanais responsáveis pela reorganização da alta bacia do rio Branco. No futuro, essa reorganização necessita ser mais bem compreendida através de datações que melhor esclareçam a cronologia de tais eventos. 

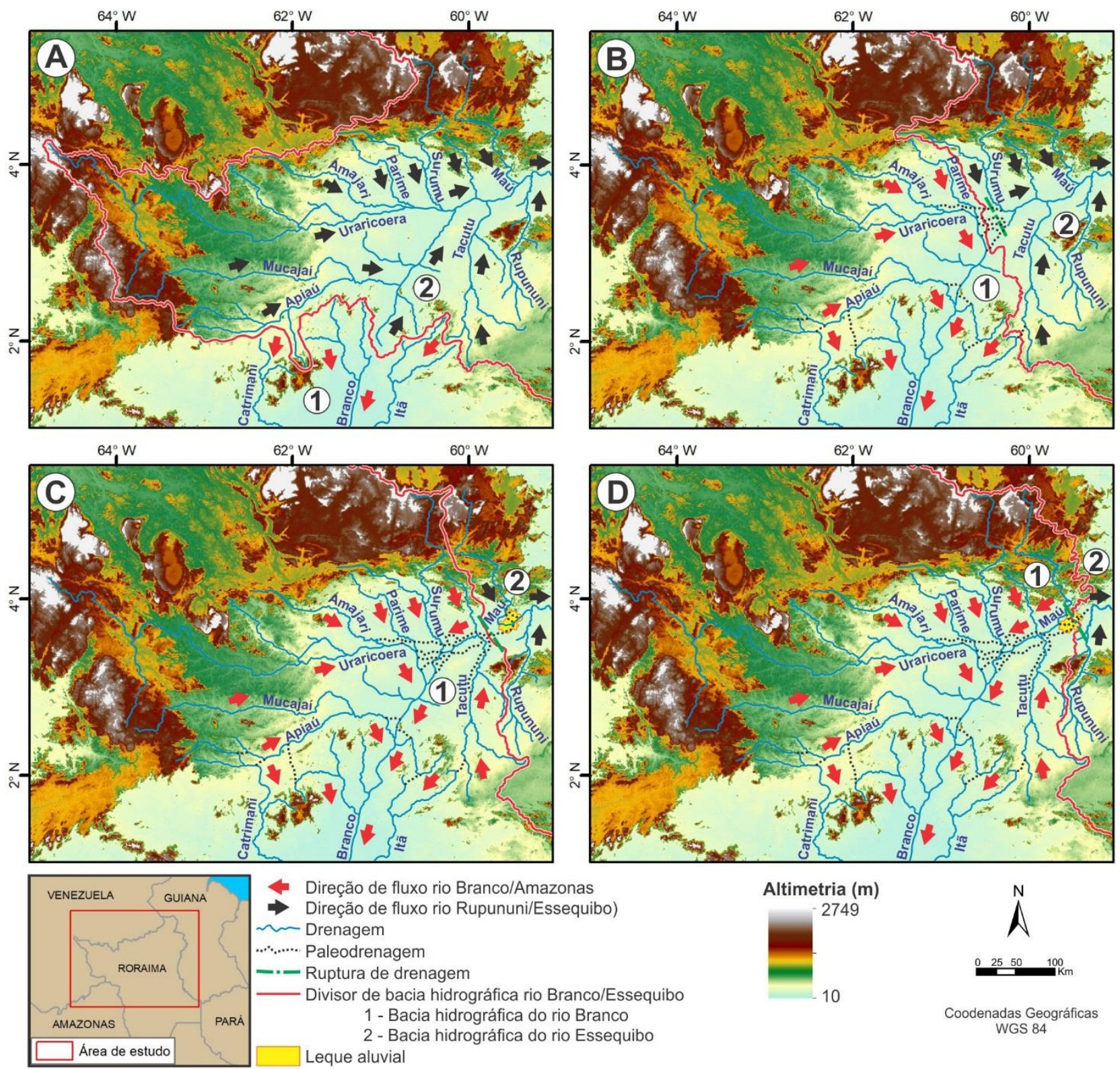

Figura 6: Modelo evolutivo para, através das capturas fluviais, demonstrar a formação da região da atual alta Bacia Hidrográfica do rio Branco.

\section{Considerações Finais}

O presente trabalho encontrou as evidências morfológicas que complementam as evidências sedimentares anteriormente levantadas por Cremon et al. (2016). Com isto comprova, indubitavelmente, que a alta Bacia Hidrográfica do rio Branco antes estava integrada à Bacia Hidrográfica do rio Essequibo. Seus resultados permitem ainda constatar que a Bacia Amazônica tem expandido sua área na sua porção setentrional e que essa expansão tende a ser um processo contínuo onde, um a um, canais fluviais que antes escoavam para o mar do Caribe, são interceptados, pirateados e desviados para sul. 
Contribuições dos Autores: Este artigo teve a colaboração de cinco autores, assim distribuída: Concepção e Metodologia: André Augusto Rodrigues Salgado, Franzmiller Almeida Nascimento e António Alberto Teixeira Gomes; Análise Formal e Validação: Franzmiller Almeida Nascimento, Breno Ribeiro Marent e António Alberto Teixeira Gomes; Preparação de dados: Franzmiller Almeida Nascimento, Breno Ribeiro Marent e António Alberto Teixeira Gomes; Escrita do artigo: André Augusto Rodrigues Salgado, Breno Ribeiro Marent, Franzmiller Almeida Nascimento; Revisão: António Alberto Teixeira Gomes e Stélio Tavares Soares Júnior; Supervisão: André Augusto Rodrigues Salgado, António Alberto Teixeira Gomes e Stélio Tavares Soares Júnior. Todos os autores leram e concordaram com a versão publicada do manuscrito.

Financiamento: Esta pesquisa foi financiada pela CAPES com uma bolsa de doutorado e pelo CNPq (301096/2018-0).

Agradecimentos: Agradecemos a CAPES e ao CNPq pelo apoio financeiro.

Conflito de Interesse: Os autores declaram não haver conflito de interesse.

\section{Referências}

1. ALBERT, J. S.; REIS, R. E. Historical Biogeography of Fresh Waters. Berkeley: University of California Pres, 2011. 388p.

2. BARBOSA, R. I. (1997). Distribuição das Chuvas em Roraima. In: BARBOSA, R. I.; FERREIRA, E. J. G.; CASTELLÓN, E.

G. (Eds.). Homem, Ambiente e Ecologia no Estado de Roraima. INPA: p. 325-335.

3. BESERRA NETA, L. C; TAVARES JÚNIOR, S. S. Geomorfologia do Estado de Roraima por Imagens de Sensores Remotos. In: SILVA, P. R. F.; OLIVEIRA, R. S. (Org.). Roraima 20 Anos As Geografias de um Novo Estado. Boa Vista: Editora da UFRR - EDUFRR, 2008, v. 1, p. 169-192.

4. BISHOP, P. Drainage Rearrangement by River Capture, Beheading and Diversion. Progress in Physical Geography, v. 19, n. 4, p. 449-473, 1995. https://doi.org/10.1177/030913339501900402.

5. CPRM - COMPANHIA DE PESQUISA DE RECURSOS MINERAIS. Programa Levantamentos Geológicos Básicos do Brasil. Carta Geológica do Brasil ao milionésimo. Boa Vista e Roraima folhas NA20 e NB20. Escala 1:1.000.000, 2004.

6. CREMON, E. H.; ROSSETTI, D. F.; SAWAKUCHI, A. O.; COHEN, M. C. L. The role of tectonics and climate in the late Quaternary evolution of a northern Amazonian River. Geomorphology, 271, p. 22-39, 2016. https://doi.org/10.1016/j.geomorph.2016.07.030.

7. GUERRA, A. T. (1957). Estudo Geográfico do Território Federal de Roraima. Rio de Janeiro, IBGE-Instituto Brasileiro de Geografia e Estatística, 252p.

8. HOORN, C.; GUERRERO, J.; SARMIENTO, G. A.; LORENTE, M. A. Andean tectonics as a cause for changing drainage patterns in Miocene northern South America. Geology, v. 23, n. 3, p. 237-240, 1995. https://doi.org/10.1130/0091-7613(1995)023. 9. HOORN, C.; WESSELINGH, F. P.; STEEGE, H.; BERMUDEZ, M. A.; MORA, A.; SEVINK, J.; SANMARTÍN, I.; SANCHEZ-MESEGUER, A.; ANDERSON, C. L.; FIGUEIREDO, J. P.; JARAMILlO, C.; RIFF, D.; NEGRI, F. R.; HOOGHIEMSTRA, H.; LUNDBERG, J.; STADLER, T.; SÄRKINEN, T.; ANTONELLI, A. Amazonia Through Time: Andean Uplift, Climate Change, Landscape Evolution, and Biodiversity. Science, 330, p. 927-931, 2010. https://doi.org/10.1126/science.1194585.

10. HOORN, C.; BOTOGÁ-A, G. R.; ROMERO-BAEZ, M.; LAMMERSTMA, E. I.; FLANTUA, S. G. A.; DANTAS, E. L.; DINO, R.; CARMO, D.A.; CHEMALE JR., F. The Amazon at sea: Onset and stages of the Amazon River from a marine record, with special reference to Neogene plant turnover in the drainage basin. Global and Planetary Change, 153, p. 51-65, 2017. https://doi.org/10.1016/j.gloplacha. 
11. NASCIMENTO, F. A.; SALGADO, A. A. R.; GOMES; A. A. T. Evidências de rearranjos fluviais no interflúvio AmazonasEssequibo - Amazônia Setentrional. Revista Brasileira de Geomorfologia, v. 20, n. 3, p. 663-671, 2019. http://dx.doi.org/10.20502/rbg.v20i3.1520.

12. REIS, N. J.; SANTOS, J. O. S.; RIKER, S. R. L.; PESSOA, M. R.; PINHEIRO, S. S. A cobertura sedimentar Roraima na serra das Surucucus - enfoque a seus ambientes deposicionais. In: Simpósio de Geologia da Amazônia, 3, Belém, 1991. Anais. Belém: SBG/NO, 1991. p.361-370.

13. REIS, N. J.; FRAGA, L. M. B. Geologia do Estado de Roraima. Relatório inédito. Manaus. CPRM, 1998. pg. 1-31.

14. REIS, N. J.; FRAGA, L. M.; FARIA, M. S. G.; ALMEIDA, M. E. Geologia do Estado de Roraima. Géologie de la France, 2-3. 2003. 71-84.

15. SACEK, V. Drainage reversal of the Amazon River due to the coupling of surface and lithospheric processes. Earth and Planetary Science Letters, 401, p. 301-312, 2014. 10.1016/j.epsl.2014.06.022

16. SILVA, E. L. (1997). A Vegetação de Roraima. In: Barbosa, R. I.; Ferreira, E. J. G.; Castellón, E. G. (Eds.) Homem, Ambiente e Ecologia no Estado de Roraima. Ed. INPA, Manaus: p. 401-415.

17. STOKES, M. F.; GOLDBERG, S. L.; PERRON, J. T. Ongoing river capture in the Amazon. Geophysical Research Letters, 45, p. 5545- 5552, 2018. https://doi.org/10.1029/2018GL078129.

18. WYNN, J. C.; SIDDER, G. B.; GRAY, F.; PAGE, N.; MENDOZA, S. V. Geology and mineral deposits of the Venezuelan Guayana Shield. U. S. Geological Survey Bulletin, n. B2124, p. A1-A7, 1993.

Esta obra está licenciada com uma Licença Creative Commons Atribuição 4.0 Internacional (http://creativecommons.org/licenses/by/4.0/) - CC BY. Esta licença permite que outros distribuam, remixem, adaptem e criem a partir do seu trabalho, mesmo para fins comerciais, desde que lhe atribuam o devido crédito pela criação original. 